\title{
Correction: BPTF regulates growth of adult and pediatric high-grade glioma through the MYC pathway
}

Adam L. Green (D) - John DeSisto - Patrick Flannery • Rakeb Lemma • Aaron Knox (D) Madeleine Lemieux • Bridget Sanford - Rebecca O'Rourke - Shakti Ramkissoon • Kristen Jones • Jennifer Perry • Xu Hui • Erin Moroze • Ilango Balakrishnan · Allison F. O'Neill · Katherine Dunn · Deborah DeRyckere · Etienne Danis · Aaron Safadi • Ahmed Gilani · Benjamin Hubbell-Engler • Zachary Nuss • Jean M. Mulcahy Levy (D) Natalie Serkova • Sujatha Venkataraman • Douglas K. Graham • Nicholas Foreman • Keith Ligon • Ken Jones • Andrew L. Kung • Rajeev Vibhakar

Published online: 22 January 2020

(c) The Author(s), under exclusive licence to Springer Nature Limited 2020

\section{Correction to: Oncogene}

https://doi.org/10.1038/s41388-019-1125-7

The original version of this Article omitted the following from the Acknowledgements:
This work was supported by the Luke's Army Pediatric Cancer Research Fund St. Baldrick's Scholar Award.

This has now been corrected in both the PDF and HTML versions of the Article. 